\title{
EDITORIAL
}

\section{Emisiones de gases de efecto invernadero y cambio climático}

\begin{abstract}
Nuestro clima está sufriendo graves alteraciones desde hace varias décadas, el Panel Intergubernamental de Cambio Climático (IPCC, por sus siglas en inglés) sostiene que el calentamiento global que venimos experimentando es inequívoco y que en su mayor parte se debe "muy probablemente" al incremento de las concentraciones de gases de efecto invernadero (GEI) generadas por actividades humanas.
\end{abstract}

Las emisiones totales de GEI antropogénicas han seguido aumentando durante 1970 hasta el 2010, con mayores incrementos absolutos de décadas hacia el final de este período. A pesar de un número cada vez mayor de las políticas de mitigación del cambio climático, las emisiones anuales de GEl crecieron en promedio 0,4 giga tonelada de dióxido de carbono equivalente (G+CO2eq) (1,3\%) por año desde 1970 hasta 2000 , y en 1,0 GtCO2eq $(2,2 \%)$ por año desde el 2000 hasta el 2010 (1).

Las emisiones totales de GEl antropogénicos en el 2000 llegaron de $40 \mathrm{GtCO}$ eq/año y el 2010 llegó a $49 \mathrm{GtCO}$ eq/año siendo los valores más altos en la historia humana; en este mismo periodo los GEl antropogénicos han aumentado en $10 \mathrm{GtCO} 2 \mathrm{eq}$, generado directamente por los sectores de energía (47\%), la industria (30\%), el transporte (11\%) y las construcciones (3\%) (1). Algunas excepciones de las grandes emisiones de dióxido de carbono (CO2) por uso de la energía son por procesos químicos (producción de cemento o cal, metalurgia, etc.) (2).

Alrededor de la mitad de las emisiones antropogénicas de CO2 acumuladas entre 1750 y 2010 se han producido en los últimos 40 años; asimismo estas emisiones proceden de la quema de combustibles fósiles y procesos industriales que contribuyeron con aproximadamente el $78 \%$ del aumento total de las emisiones de GEI entre
1970 y 2010, un porcentaje de contribución similar para el período 2000 al 2010 (1); también el aumento de la concentración mundial de $\mathrm{CO} 2$-en una parte apreciable pero menores causado por los cambios de uso de la tierra y por la agricultura. El aumento de metano ha sido menos rápido desde comienzos de los años 90, en concordancia con las emisiones totales (como suma de fuentes antropogénicas y naturales), que han sido casi constantes durante ese período (3).

Tres factores influyen en la temperatura promedio de la superficie de la Tierra:

El primero es determinado por el desarrollo de nuestra estrella, el Sol, el cual era $30 \%$ menos cálido a principios de nuestro sistema planetario. Sin embargo, hoy el calentamiento supera la media global y continuará calentándose pero a escala de miles de millones de años, lo cual hace de ese factor una constante para el Homo Sapiens.

El segundo es determinado por los ciclos de Milankovitch el más relevante de los cuales tienen que ver con que tan excéntrica es la elíptica que traza la Tierra en su orbita alrededor del sol que varía en ciclos de 100000 y 400000 años, haciéndose mas o menos alargada, modificando las distancias máximas al sol, con lo que las estaciones se hacen mas extremas. También este factor termina siendo una constante para el Homo Sapiens $(2,4)$.

El tercer factor son las concentraciones de $\mathrm{CO} 2$ y otros $\mathrm{GEI}$, que pueden variar por factores geológicos, como el vulcanismo, en el curso de miles de años. Ahora el hombre las ha hecho variar a la alza, en el lapso de solo doscientos años. Un gran forzamiento antropogénico para el ciclo biogeoquímico del carbono con el consiguiente incremento de las concentraciones y de la temperatura superficial promedio (2). 
Con base en los conocimientos científicos actuales, el previsible incremento de las concentraciones de GEl en el curso del siglo anuncia con bastante certeza que, si bien la temperatura superficial promedio global es de $14,5^{\circ} \mathrm{C}$ (tal y como se ha mantenido en los últimos 12 mil años, durante el Holoceno), para el 2100 andaríamos entre 18,5 y $19^{\circ} \mathrm{C}$, lo cual sería una verdadera catástrofe por los impactos adversos en la disponibilidad de recursos naturales para la economía humana. Agua, aire, tierra y alimentos serán insuficientes para una población que habría rebasado los 10 mil millones de habitantes (2).

En el mundo, el crecimiento económico y de población siguen siendo los impulsores más importantes del aumento de las emisiones de CO2 procedentes de la quema de combustibles fósiles (1) y este incremento constituye una de las causas del cambio climático global. La contribución del crecimiento de la población entre los años 2000 y 2010 se mantuvo más o menos idéntica a las tres décadas anteriores, mientras que la contribución del crecimiento económico ha aumentado considerablemente (1).

El cambio climático es uno de los mayores problemas de nuestro tiempo y existe una profunda alarma porque las emisiones de GEI siguen aumentando en todo el mundo.

Preocupa profundamente que todos los países, en particular los países en desarrollo, sean vulnerables a los efectos adversos del cambio climático y ya estén experimentando mayores efectos, entre ellos sequías persistentes y fenómenos meteorológicos extremos, aumento del nivel del mar, erosión costera y acidificación de los océanos, que amenazan todavía más la seguridad alimentaria y las medidas para erradicar la pobreza y lograr el desarrollo sostenible. Así pues, se pone de manifiesto que la adaptación al cambio climático representa una prioridad mundial inmediata y urgente.

No obstante la naturaleza mundial del cambio climático requiere la cooperación más amplia posible de todos los países y su participación en una respuesta internacional efectiva y apropiada, con miras a acelerar la reducción de las emisiones mundiales de GEI (5).

Es importante recordar que la Convención Marco de las Naciones Unidas sobre el Cambio Climático dispone que las partes deben proteger el sistema climático en beneficio de las generaciones presentes y futuras, sobre la base de la equidad y de conformidad con sus responsabilidades comunes pero diferenciadas y sus respectivas capacidades, principios y responsabilidades que los países miembros ya tienen como obligación en sus propias legislaciones.

\section{Referencias bibliográficas:}

1. Intergovernmental Panel on Climate Change (IPCC). Working Group III contribution to the IPCC 5th Assessment Report "Climate Change 2014: Mitigation of Climate Change". Cambridge: Cambridge University Press; 2013. http://mitigation2014.org/ report/final-draft

2. Gonzáles DG. Energía y cambio climático. Revista Derecho Ambiental y Ecología. 2013; 10(55): 61-63.

3. IPCC. Cambio climático 2007, informe de síntesis. Ginebra: Grupo Intergubernamental de Expertos sobre el Cambio Climático; 2007.

4. National Oceanic and Atmospheric Administration. Astronomical Theory of Climate Change. Carolina del Norte: NOAA; 2013. http://www.ncdc.noaa.gov/paleo/ milankovitch.html

5. Conferencia de las Naciones Unidas sobre el desarrollo sostenible "El futuro que queremos". Res 66/288 de 11 de setiembre de 2012. Resolución aprobada por la Asamblea General, (30 de enero de 2013).

Wilfredo Bulege

Editor jefe 